\title{
Energy Depletion in Culture
}

\section{Adenine Nucleotides Are Altered as In Vivo}

\author{
BRADFORD T. STOKES, RUTH A. ALTSCHULD, \\ Charlene M. HOHL, QIAN LI, AND DOGGLAS K. ANDERSON' \\ Departments of Physiology and Physiological Chemistry, \\ The Ohio State University, Columbus, $\mathrm{OH} 43210$ \\ and 'VA Medical Center and The Department of Neurology, \\ University of Cincinnati, Cincinnati, $\mathrm{OH} 45220$.
}

Received February 12, 1991; Accepted March 29, 1991

\begin{abstract}
Modeling of ischemic phenomena in vitro has been hindered by the inability to create specific alterations in the variables of interest over a defined time-frame. In particular, changes in the adenine nucleotide pool have been quite difficult to mimic because of the putative low metabolic rate in culture and the long times necessary to achieve even partial chemical energy depletion. Here we present evidence for a rapid method of producing a profound chemical energy depletion with the combination of a NADH dehydrogenase inhibitor (amytal) and a mitochondrial proton ionophore (CCCP). Treatment with our protocol in enriched spinal cultures results in a $40 \%$ decrease in ATP within 2 min and a fall to one-third of control values by $15 \mathrm{~min}$. The overall pool size of the total adenine nucleotides is decreased $46 \%$ by $15 \mathrm{~min}$ and does not completely recover after $5 \mathrm{~min}$ of reenergization. The ATP/ADP ratio declines to one-third of control values during deenergization and returns to control values after $5 \mathrm{~min}$ in control buffer. Such a loss of the total adenylate pool closely mimics that seen in vivo during ischemia and provides an in vitro model system in which the effects of the combination of this means of cellular injury with others (e.g., excitotoxins) may be examined.
\end{abstract}

Index Entries: Deenergization; tissue culture; energy metabolism; ATP depletion.

*Author to whom all correspondence and reprint requests should be addressed. 


\section{INTRODUCTION}

Injury to neuronal cells is associated with a decline in high-energy phosphates, a loss of cation homeostasis, and possibly, an increase in reactive oxygen radicals. (Siesjö, 1988b). Of these possibilities, interest in energy depletion is intensifying, because of its rapid and profound influence on cellular homeostasis and its potential interaction with excitotoxic modes of cell injury (Choi et al., 1987). The exact linkage between these events and the physiological and pathological sequelae of neural injury at the cellular level, particularly in the spinal cord, has not been clearly defined.

A variable rate of energy depletion is characteristic of ischemic or traumatically induced spinal-cord injury. Within 5 min after cord contusion injury, ATP levels and energy charge have fallen to a fraction of their control values (Hayashi et al., 1984; Vink et al., 1987, 1988), particularly in the gray matter (Walker et al., 1979; Anderson et al., 1980). During spinal ischemia a more gradual decline in these reserves takes place and energy metabolites respond quickly to the restoration of control conditions (Anderson et al. 1983; Danielisovä et al., 1987). Corresponding alterations in other of the adenine nucleotide metabolites have been examined (Siesjö, 1988a, 1988b) in vivo and the altered chemistry seems to parallel that seen elsewhere in the cerebrum (Schultz \& Lowenstein, 1978) and other tissues known to be sensitive to energy depletion ( $\mathrm{Li}$ et al., 1988). Because of an increasing interest in these pathways in mechanisms of cell death and the ability to mimic these phenomena in cultures (Choi et al., 1988), we have begun the characterization of processes of deenergization in spinal tissue cultures. From the studies reported here, it is apparent that chemical deenergization in such cultures can be used to create alterations in adenine nucleotide profiles much like those seen in situ. By increasing the precision with which adenine nucleotide patterns can be characterized in vitro (Hammer et al., 1988), we should be able to create model systems in which the mechanistic interpretation of changes in adenine nucleotide profiles can take place.

\section{METHODS}

\section{Neuronal-Enriched Cultures}

Spinal cultures are prepared from timed pregnant mice, $C D-1$ (Charles River, NY, USA) that are sacrificed by cervical dislocation on day 13 (Demediuk et al., 1985). Briefly, the embryos are removed and placed in sterile HEPES buffered salt solution $\left(\mathrm{D}_{1} \mathrm{GH}, 137 \mathrm{mM} \mathrm{NaCl}, 5.35\right.$ $\mathrm{mM} \mathrm{KCl}, 2.2 \mathrm{mM} \mathrm{KH} \mathrm{PO}_{4}, 16.6 \mathrm{mM}$ glucose, $21.9 \mathrm{mM}$ sucrose, $1.2 \mathrm{ng} /$ $\mathrm{mL}$ phenol red, and $9.8 \mathrm{mM}$ HEPES, $\mathrm{pH}$ 7.4). Using stereomicroscopic visualization, the spinal cord is gently teased away from the embryo leaving a connection at the cephalad end. The meninges are teased apart 
along the central canal and then stripped away, removing in the process all dorsal root ganglia. The spinal cords are then minced with Vannas scissors, then trypsinized in $2 \mathrm{~mL}$ of a $0.25 \%$ solution containing $7 \% \mathrm{CO}_{2}$ culture. After trypinsinization, the tissue is transferred to $3 \mathrm{~mL}$ of bicarbonate-buffered MEM with Earle's salts containing $10 \%$ horse serum, $1 \%$ L-glutamine and $1 \%$ deoxyribonuclease (10/10 MEM) and the settled tissue triturated with a sterile Pasteur pipet to dissociate the cells. The tissue is allowed to settle again, retriturated, and the supernatant of dispersed cells is then plated onto collagen-coated $100-\mathrm{mm}$ culture dishes at a density of approx $1.0 \times 10^{6}$ cells $/ \mathrm{mL}$. All assays were performed on confluent preparations of these cells after $21 \mathrm{~d}$ in culture. After enrichment procedures outlined in Demediuk et al., (1985), we have found $80-90 \%$ of the protein in the cultures to be of neuronal origin.

\section{Energy Depletion Protocols}

These cells were deenergized using an established protocol that we have used with other isolated cell lines and those in culture ( $\mathrm{Li}$ et al., 1988, 1989; Stokes et al., 1989). Briefly, the protocol is chosen because of the rapid and reversible nature of its effects on the adenine-nucleotide pools. Cells are exposed in their normal media (Krebs-Henseleit with 10 $\mathrm{mM}$ pyruvate) to a combination of a NADH dehydrogenase inhibitor (amytal; $3 \mathrm{mM}$ ) and CCCP (carbonyl cyanide m-chlorophenylhydrazone; $2.0 \mu \mathrm{M}$ ) that allows us to mimic the prompt changes that occur during cerebral ischemia in vivo.

\section{Adenine Nucleotide Analysis}

For ATP and total nucleotide analyses, the cells were frozen on coverslips on dry ice after treatment. These were then scraped with a rubber policeman into a $100-\mu \mathrm{L}$ drop of $0.6 \mathrm{M}$ perchloric acid in a $1.5-\mathrm{mL}$ microfuge tube cooled by liquid nitrogen, and homogenized with a motor-driven microhomogenizer (Biomedix, Middlesex, UK) as described previously for endomyocardial biopsies (Hammer et al., 1988). The microfuge tube and contents were centrifuged for $1 \mathrm{~min}$ at 15,000 rpm in an Eppendorf microfuge. The acid extract was then removed and neutralized from Freon-trioctylamine.

ATP and other nucleotides, nucleosides, and nucleobases of interest were resolved and quantified by HPLC methods developed at Ohio State University (Altschuld et al., 1987; Hammer et al., 1988). The residue was subsequently dissolved in $0.1 \mathrm{M} \mathrm{NaOH}$ and total noncollagen protein assayed by the Lowry method. Metabolic data are therefore expressed in terms of total cellular protein.

\section{RESULTS AND DISCUSSION}

Energy metabolites are rapidly degraded by chemical deenergization (Fig. 1). After being subjected to the combination of an NADH dehy- 


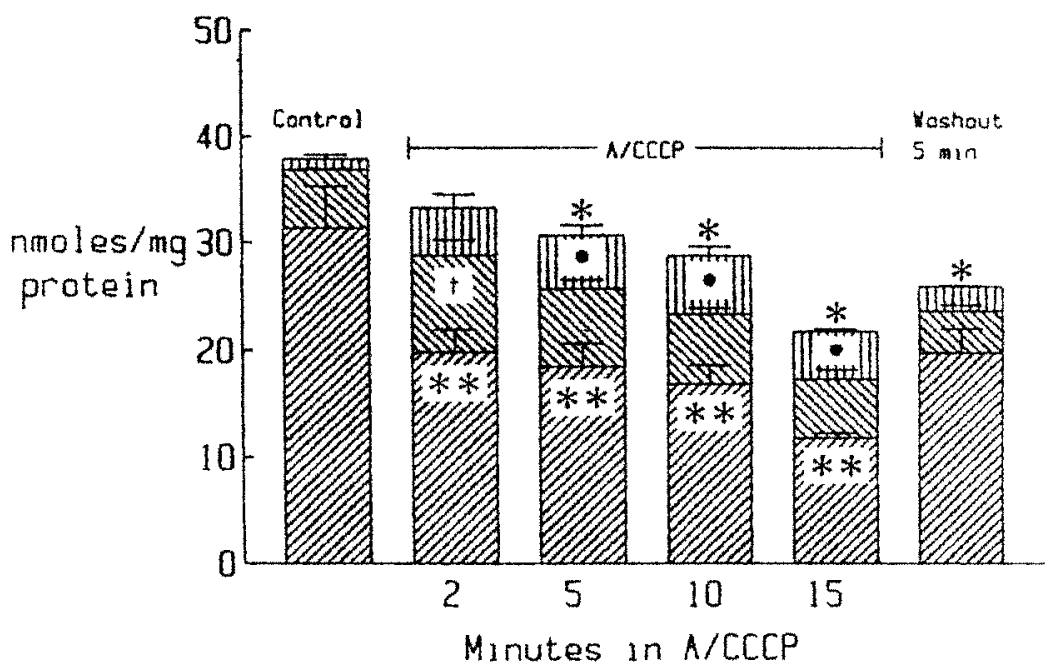

Fig. 1. Energy depletion and adenine nucleotides in culture. Cells were harvested from cultures after freezing with liquid nitrogen, homogenized, and processed for HPLC as before (Hammer et al., 1988). Cells were also assayed for total protein, and results are therefore expressed as nanomoles of metabolites/per milligram protein. Cultures were sampled at 2, 5, 10, and $15 \mathrm{~min}$ after amytal/ CCCP incubation and 5 min after postincubation washout. ATP changes; ADP; 1 , AMP. All data are expressed as mean \pm $\mathrm{SEM} ; N=6$ for all times sampled except for $15 \mathrm{~min}$, when $N=4$ in this and the following figure. The total height of the bars indicates the total adenine nucleotide pool.

drogenase inhibitor (amytal) and a proton ionophore (CCCP), ATP falls $40 \%$ within $2 \mathrm{~min}$ and is only one-third of its control value after $15 \mathrm{~min}$. Only partial restoration takes place after $5 \mathrm{~min}$ of washout $(40 \%$ of normal). The rapidity of this loss is therefore like that which occurs during spinal ischemia and traumatic injury (Hayashi et al., 1984; Vink et al., 1987, 1988). The decline of ATP occurs concomitantly, with a prompt increase in ADP (100\%) by 2 min and a return to normal levels by 15 min; restoration of the ADP pool is incomplete after $5 \mathrm{~min}$ of recovery. The AMP pool increases for up to $10 \mathrm{~min}$ after deenergization, falls by $10 \%$ at $15 \mathrm{~min}$, and is only $50 \%$ of the 15 -min-deenergized value after $5 \mathrm{~min}$ of recovery. The overall size of the adenine nucleotide pool falls precipitously during deenergization (decrease of $46 \%$ ) and is not restored during the $5 \mathrm{~min}$ of reenergization.

The loss of total adenylates in these protocols most likely involves the production and cellular efflux of adenosine, inosine, and hypoxanthine (Altschuld et al., 1987; Geisbuhler et al., 1984). However, cell death in a fraction of the population could also cause a decline in measured adenine nucleotides. The incomplete recovery of ATP/ADP in this 


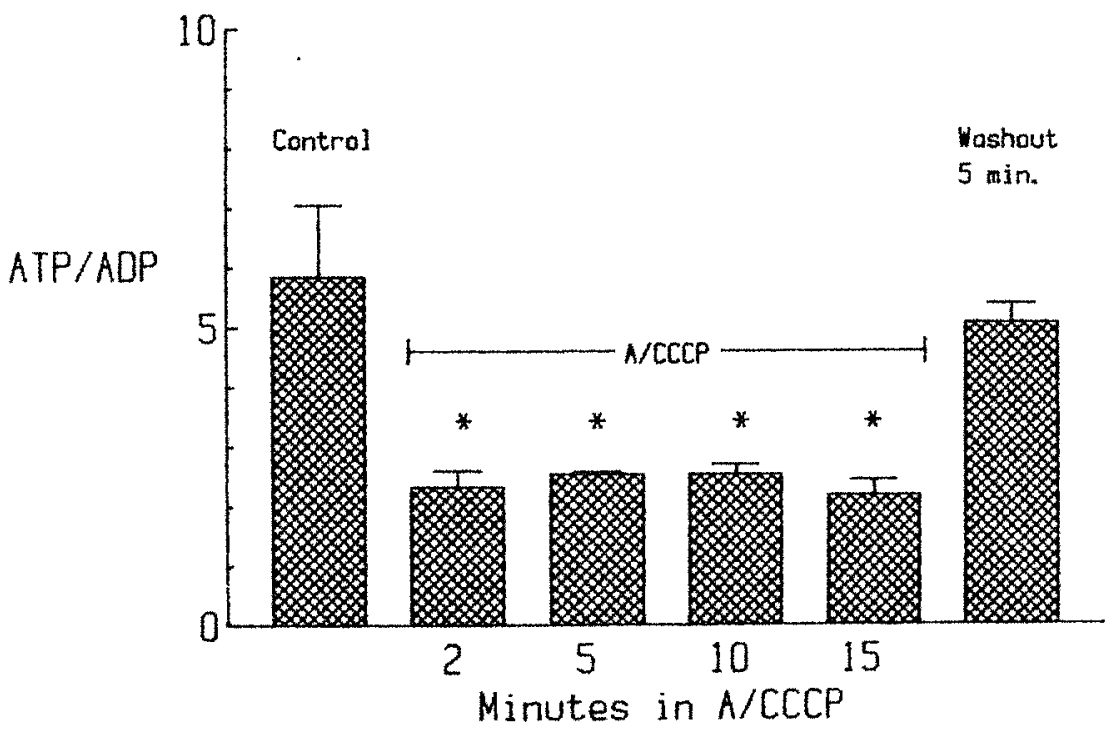

Fig. 2. ATP/ADP ratios for all sampled times and experimental protocols. Note the prompt diminution to a fixed ratio and the rapid rebound during reenergization.

protocol may also be explained by intracellular compartmentalization of ADP.

We have therefore shown that cultured spinal neuronal cells lose ATP and total adenine nucleotides when challenged with amytal and CCCP. This is associated with a decline in the ATP/ADP ratio, as would be predicted on the basis of similar studies (Altschuld et al., 1987; Li et al., 1989) with other excitable cells (Fig. 2).

Upon removal of these compounds, there is a rebound in the ATP/ ADP ratio to values indistinguishable from controls $(p<0.2)$, whereas the size of the total adenine nucleotide pool remains depressed. We interpret this to mean that any cytosolic ADP that is available is rephosphorylated after this brief recovery. In a previous study, we have also shown that these protocols result in significant alterations in intracellular calcium metabolism and prompt changes in proteolytic actions within the cell (Stokes et al., 1990). Briefly, deenergization results in increases in intracellular free calcium, to over $1.0 \mu M$ in $<5 \mathrm{~min}$, and a significant loss of cytoskeletal proteins (F-actin and G-tubulin) within 10 min. Such approaches therefore provide a model system in which these various components of the ischemic response in vivo can be isolated and studied in a more defined way in tissue culture. As we attempt to identify the time-course and magnitude of the important events in the ischemic responses in vivo, such models will be of considerable value in determining the relative role of the various cytotoxic events (e.g., excitotoxins) that occur during cell death. Future experiments will provide us 
with a more complete description of the range of metabolic responses to reversible and irreversible cell injury and indicate the dominant pathways for nucleotide breakdown and resynthesis in this cell type.

\section{REFERENCES}

Altschuld R. A., Gamelin L. M., Kelley R. E., Lambert M. R., Apel L. E., and Brierley G. P. (1987) Degradation and resynthesis of adenine nucleotides in adult rat heart myocytes. J. Biol. Chem. 262, 13527-13533.

Anderson D. K., Means E. D., Waters T. R., and Spears C. J. (1980) Spinal cord energy metabolism following compression trauma to the feline spinal cord. 1. Neurosurg. 53, 375-380.

Anderson D. K., Behbehani M. M., Means E. D., Waters T. R., and Green E. S. (1983) Susceptibility of feline spinal cord energy metabolism to severe incomplete ischemia. Neurology. 33, 722-731.

Choi D. W., Koh J. Y., and Peters S. (1988) Pharmacology of glutamate neurotoxicity in cortical cell culture: Attenuation by NMDA antagonists. I. Neurosci. 8, 185-196.

Choi D. W., Maulucci-Gedde M., and Kriegstein A. R. (1987) Glutamate neurotoxicity in cortical cell culture. 7 . Neurosci. 7, 357-368.

Danielisovä V., Chavko M., and Kehr J. (1987) Adenine nucleotide levels and regional distribution of ATP in rabbit spinal cord after ischemia and recirculation. Neurochem. Res. 12, 241-245.

Demediuk P., Anderson D. K., Horrocks L. A., and Means E. D. (1985) Mechanical damage to murine neuronal-enriched cultures during harvesting: Effects on free fatty acids, diglycerides, $\mathrm{Na}+, \mathrm{K}+-\mathrm{ATP}$ ase and lipid peroxidation. In Vitro Cell. Develop. Biol, 21, 569-574.

Geisbuhler T., Altschuld R. A., Trewyn R. W., Ansel A. Z., Lamka K. G., and Brierley G. P. (1984) Adenine nucleotide metabolism and compartmentalization in isolated adult rat heart cells. Circ. Res. 54, 536-546.

Hammer D. F., Unverferth D. V., Kelley R. E., Harvan P. A., and Altschuld R. A. (1988) Extraction and measurement of myocardial nucleotides, nucleosides, and purine bases by high-performance liquid chromatography. Anal. Biochem. 169, 300-305.

Hayashi N., Tsubokawa T., and Green B. A. (1984) Changes in energy metabolism and spinal cord blood flow following severe spinal cord injury. No. Shinkei. Geka. 12, 923-930.

Li Q., Altschuld R. A., and Stokes B. T. (1988) Myocyte deenergization and intracellular free calcium dynamics. Am. J. Physiol. 255, C162-C168.

Li Q., Hohl C. M., Altschuld R. A., and Stokes B. T. (1989) Energy depletion' repletion and calcium transients in single cardiomyocytes. Am. I. Phys. (Cell) 257, C427-C434.

Schultz V. and Lowenstein J. M. (1978) The purine nucleotide cycle. Studies of ammonia production and interconversions of ademine and hypoxanthine nucleotides and nucleosides by rat brain in situ. J. Biol. Chem. 253, 19381943.

Siesjö B. K. (1988a) Hypoglycemia, brain metabolism, and brain damage. Diabetes Metab. Rev. 4, 113-144. 
Siesjö B. K. (1988b) Historical overview. Calcium, ischemia, and death of brain cells. Ann. NY Acad. Sci., 522, 638-661.

Stokes B. T., Li Q., Altschuld R. A., Batten B. E., and Anderson D. K. (1990) Energy depletion, calcium and the cytoskeleton: A model for trophic factors in the Central Nervous System, in Trophic Factors and the Nervous System (Horrocks L. A., Neff N. H., Yates A. I., and Hadjiconstantinou M., eds), Raven, New York, pp. 279-292.

Vink R., McIntosh T. K., Weiner M. W., and Faden A. I. (1987) Effects of traumatic brain injury on cerebral high-energy phosphates and $\mathrm{pH}$ : A 31P magnetic resonance spectroscopy study. J. Cereb. Blood Flow Metab. 7, 563571.

Vink R., McIntosh T. K., Yamakami I., and Faden A. 1. (1988) 31P NMR characterization of graded traumatic brain injury in rats. Magn. Reson. Med. $6,37-48$.

Walker J. G., Yates R. R., and Yashon D. (1979) Regional canine spinal cord energy state after experimental trauma. I. Neurochem. 33, 397-401. 